Research, part of a Special Feature on Effects of Roads and Traffic on Wildlife Populations and Landscape Function

\title{
Behavioral Responses of Northern Leopard Frogs (Rana pipiens) to Roads and Traffic: Implications for Population Persistence
}

\author{
$\underline{\text { Julie Bouchard }}^{1}, \underline{\text { Adam T. Ford }}^{1}, \underline{\text { Felix E. Eigenbrod }}^{1}$, and Lenore Fahrig ${ }^{1}$
}

\begin{abstract}
A key goal in road ecology is to determine which species are most vulnerable to the negative effects of roads on population persistence. Theory suggests that species that avoid roads are less likely to be negatively affected by roads than those that do not avoid roads. The goal of this study was to take a step toward testing this prediction by evaluating the behavioral response to roads and traffic of a species whose populations are known to be negatively affected by roads and traffic, the northern leopard frog (Rana pipiens). We studied the movement patterns of northern leopard frogs during their spring migration from overwintering sites in a river to various breeding ponds that were disconnected from the river by roads. We performed short-distance translocations of migrating frogs, followed them visually, and documented their movement coordinates following each hop, both near the roads and in non-roaded areas. We found that frogs took longer to move near roads with more traffic and that their movement was quickest in areas without roads nearby. Frogs tended to deviate more from a straight-line course when they were released near roads than compared with control areas, but this response was independent of traffic volume. All frogs released near roads attempted to cross the road. On very low traffic roads (10.86 mean vehicles per hour), $94 \%$ of frogs crossed the road successfully, whereas at higher traffic roads (58.29 mean vehicles per hour) $72 \%$ were successful. Our results suggest that frog's inability to avoid going onto roads and their slow movement combine to make them particularly vulnerable to road mortality, which likely explains the strong negative effects of roads on frog population abundance. Conservation efforts should focus on preventing frogs from accessing the road surface through the use of drift fencing and culverts.
\end{abstract}

Key Words: breeding dispersal; habitat fragmentation; highway; migration; movement; road avoidance; road mortality

\section{INTRODUCTION}

In their research agenda for road ecology, Roedenbeck et al. (2007) list five important research questions. Their first and probably most important question is, "Under what circumstances do roads affect population persistence?" Because it is a probability, population persistence or viability cannot be measured directly, so an effect of roads and traffic on population persistence is inferred from a change in population size. Roads and traffic have been shown to reduce population sizes of many species (e.g., Jensen et al. 1986, Fahrig et al. 1995, Boarman and Sazaki 2006, Roedenbeck and Voser 2008; reviewed in Fahrig and Rytwinski, submitted). In other species, roads seem to have very little effect (e.g., Garland and Bradley 1984, Munguira and Thomas 1992; reviewed in Fahrig and Rytwinski, submitted) or even positive effects on population size (e.g., Johnson and Collinge 2004, Rytwinski and Fahrig 2007; reviewed in Fahrig and Rytwinski, submitted). Given that we cannot evaluate the effects of roads on every species in every situation of interest, it is important to be able to predict which species are likely to show negative effects of roads, so that we can tailor mitigation measures to those species.

Jaeger et al. (2005) predicted that the effect of roads on population persistence depends on the interaction between the behavioral response(s) of the species to roads and the mechanism(s) through which roads are likely to affect the species. The three main mechanisms are habitat loss, habitat inaccessibility (movement barrier), and direct mortality. Behavioral avoidance of both roads and the traffic 
on them is predicted to influence the effects on population persistence of all three mechanisms in complex and sometimes compensatory ways (Jaeger et al. 2005). For example, species that behaviorally avoid venturing onto the road surface will not suffer direct mortality due to collisions with vehicles, but important habitats on the other side of the road will be inaccessible (Ford and Fahrig 2008). In the long term, both mortality and avoidance effects may lead to reduced gene flow among populations separated by roads. This, in turn, can decrease fitness and further reduce population viability.

This leads to the question: are the species that avoid roads or the species that do not avoid roads more likely to show negative effects of roads on population persistence? In a modeling study, Jaeger and Fahrig (2001) predicted that, all else being equal, species that avoid roads are less likely to be negatively affected by roads than those that do not avoid roads. However, testing this prediction is not yet possible because to do so would require information on road avoidance behavior for a large number of species and an estimate of the magnitude of population declines associated with roads for each of these species. The prediction in Jaeger and Fahrig (2001) would be supported if species that do not avoid roads generally show stronger population declines associated with roads than do roadavoiding species. The overall goal of this paper is to make a step toward filling this research gap by evaluating the behavioral response to roads and traffic of a species whose populations are known to be negatively affected by roads and traffic.

Many species of amphibians show strong negative effects of roads on population size and distribution (reviewed in Fahrig and Rytwinski, submitted). Most authors suggest that the negative effects of roads on amphibians are due to traffic mortality. The assumption is that amphibians do not behaviorally avoid roads, so their populations are highly susceptible to the negative effects of traffic mortality. However, Eigenbrod et al. (2008a) found that "accessible habitat," i.e., the amount of habitat accessible to an amphibian population without crossing a road, was a stronger predictor of species richness than total habitat. They suggest this could imply that some amphibians behaviorally avoid crossing roads, particularly roads with high traffic levels. This conclusion is consistent with Gibbs (1998), who found that amphibians were less likely to cross forest-road edges than other forest edge types and Mazerolle et al. (2005), who found that amphibians placed on the road surface did respond to approaching vehicles. However, to date there are no studies of the behavior of amphibians as they approach a road. This information is needed to evaluate the hypothesis above.

Our purpose was to determine how migrating northern leopard frogs (Rana pipiens) respond to roads and traffic. Northern leopard frog populations are known to be negatively affected by roads (Pope et al. 2000, Carr and Fahrig 2001, Eigenbrod et al. 2008 b), but we do not know how individuals from this species respond to roads or traffic as they approach the road surface. We asked the following questions: (i) do migrating northern leopard frogs respond to roads and does this response lead to avoidance? (ii) if so, does the magnitude of response or the probability of avoidance depend on traffic volume? and (iii) for those frogs that attempt to cross a road, what is the probability of being killed by a vehicle and does this depend on traffic volume? To evaluate frogs' response to roads (Question i) we reasoned that they should move more slowly when approaching roads compared with movement in areas without roads nearby. They should also tend to deviate away from a road the closer they are to it. If traffic volume (Question ii) affects frog movement, then these responses (i.e., speed and direction) should be stronger at high-traffic roads than at low-traffic roads, and fewer individuals should attempt to cross a high-traffic road than a low-traffic road. Lastly, if frogs do not avoid roads, then we expect that mortality will be higher at hightraffic sites than at low-traffic sites (Question iii).

\section{METHODS}

This study was conducted near Ottawa and Kemptville, Ontario, Canada (approximately $\left.45.017741^{\circ} \mathrm{N}-75.644778^{\circ} \mathrm{W}\right)$. The subjects were northern leopard frogs on their spring migration from overwintering sites in the Rideau River to various breeding ponds. We selected study sites close to the river and at locations where northern leopard frogs are known to intersect roads at approximately $90^{\circ}$ on their way to breeding ponds (Fred Schueler, personal communication). The study sites consisted of $10 \times 20 \mathrm{~m}$ bands of habitat (Fig. 1), in which the movement behavior of northern leopard frogs was observed. Two such bands were immediately adjacent to low-traffic roads, two were adjacent to high-traffic roads, and two control bands were more than $100 \mathrm{~m}$ away from the roads, for a total of six study sites. All bands 
Fig. 1. Monitored band of habitat at field sites (a) with and (b) without roads. The white star represents the origin of the coordinate system and where we began recording frog movements. Dotted black lines correspond to the boundaries of the $3.3 \mathrm{~m}$ movement bands used to analyze angular deviation of frog movement direction.

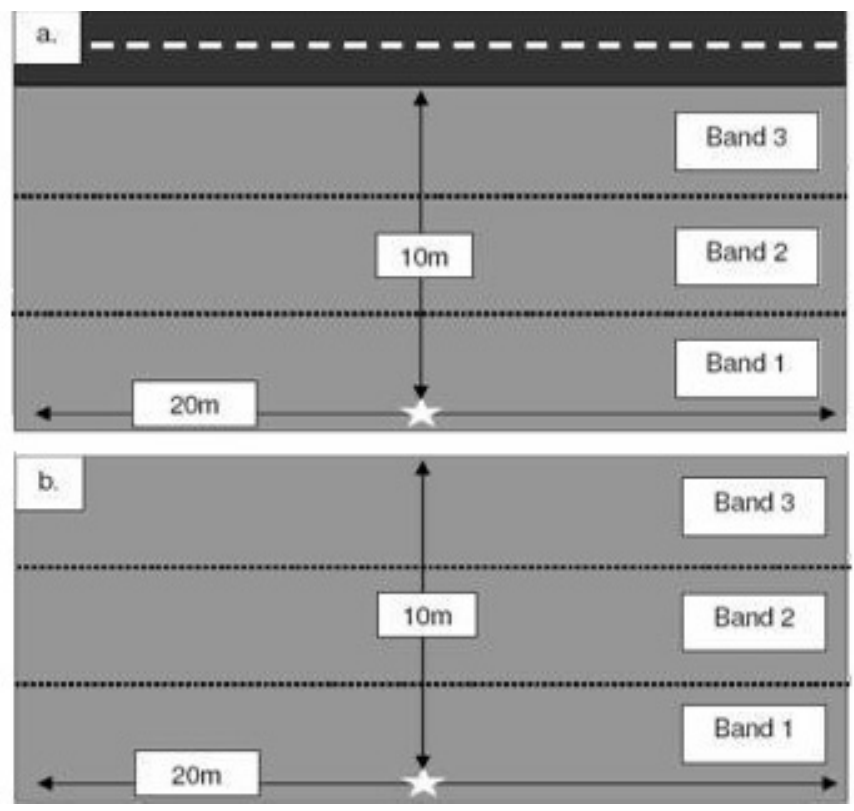

were between the river and the road. For our purposes, the habitat-road edge occurred where the gravel shoulder of the road abuts permanent vegetation cover. Each band of habitat was set up as a Cartesian plane; we used a tape, graduated with reflective tape, to create an $\mathrm{x}$-axis along the $20-\mathrm{m}$ edge of the band and a y-axis along the 10-m edge. The $\mathrm{x}$-axis was graduated from $-10 \mathrm{~m}$ to $10 \mathrm{~m}$, the $\mathrm{y}$-axis from $0 \mathrm{~m}$ to $10 \mathrm{~m}$ and the origin $(0,0)$ served as a starting point for our observations.

At each study site, we caught northern leopard frogs by hand as they approached the road. We put the captured frogs, one at a time, in an overturned bucket for $2 \mathrm{~min}$, placed the bucket at the origin of the Cartesian place, and then slowly lifted it to allow the frog to escape in its chosen direction. All frogs released continued to move in their original direction of travel. An observer standing outside the band of habitat, $5 \mathrm{~m}$ away from the origin, visually followed the progression of the frogs using a flashlight equipped with a red filter and recorded the landing coordinates of each hop to the closest $0.25 \mathrm{~m}$. Data were recorded on audio tapes, from which time sequences were later extracted. We observed that frogs stopped moving when we used an unfiltered flashlight, whereas the red light did not seem to alter the frogs behavior. At sites adjacent to roads, we also recorded the fate of each frog after it had crossed the $10-\mathrm{m}$ band of habitat and ventured onto the road surface. We took the ambient air temperature during each trial with a handheld thermometer. Data collection occurred on consecutive nights from 13 April to 21 April 2004. Two to four sites were visited each night, including at least one representative from two different site treatments.

We used categorical traffic volumes (high or low) in our analyses. To calibrate these categories, we visited the test sites on three or four occasions each between 13 April 2004 and 21 April 2004. On each of these visits, we counted the number of passing vehicles from both directions for $30 \mathrm{~min}$. These traffic counts provide an estimate for the actual number of vehicles passing along the road while we observed the frogs. We only counted traffic during the same time of day when we observed frogs moving (i.e., 1900-0130 h), although our traffic counts occurred on different nights than the nights we observed frog movement. The two low-traffic sites had a mean (SE) hourly traffic volume of 10.86 (1.14) vehicles and the two high-traffic sites had a mean hourly traffic volume of 58.29 (4.75) vehicles. 
Table 1. Type I ANOVA of the effects of treatment and temperature on the time taken by frogs (seconds) to cross $10 \mathrm{~m}$. Adjusted $\mathrm{R}^{2}$ for the model $=0.53$

\begin{tabular}{llll}
\hline \hline Source & DF & F & $P$ \\
\hline Corrected Model & 3 & 73.516 & $<0.0001$ \\
Temperature & 1 & 144.986 & $<0.0001$ \\
Treatment & 2 & 37.781 & $<0.0001$ \\
(control, low traffic, high traffic) & & & \\
Error & 189 & & \\
Total & 193 & & \\
\hline
\end{tabular}

Both road types included low ditches and level road surfaces.

All animal collecting and handling procedures were approved by the Carleton University Animal Care Committee in 2004.

\section{Data Analysis}

To determine whether the frogs slowed their movement when approaching a road, and whether this depended on traffic level, we analyzed the time taken to cross the 10-m bands using an ANOVA with categorical variables for both treatment (hightraffic road, low-traffic road, no road) and temperature. We statistically controlled for temperature in this analysis using sequential sums of squares, because frog activity increases with temperature and changes in temperature over the duration of the study could otherwise obscure the potential effects of treatment on crossing time.

To determine if traffic affects movement direction, we further subdivided each $10-\mathrm{m}$ band into equal length 3.3-m bands (bands 1, 2, and 3 in Fig. 1). Within each band, we calculated the deviation of each hop from a straight course toward the road for each movement segment. As we are only interested in the directionality of movement with respect to the road surface, we calculated all deviations as having a maximum value of $180^{\circ}$ and a minimum value of $0^{\circ}$, irrespective of whether the deviation was to the left or to the right as the frog approached the road. A deviation value of $0^{\circ}$ indicates movement directly toward the road. We calculated the mean deviation per individual for each band as the response variable. We tested for an effect of distance to the road, temperature, and treatment (control, low, or high traffic) on mean deviation using a repeated measures ANOVA with the distance from the road category as the repeated variable. Thus, distance is included in the model as an interaction with temperature and treatment. We first verified if our repeated measures design met the assumption of sphericity by performing a Mauchly's Test. This test indicates if the variancecovariance matrix of the dependent variable is circular (Huynh and Mandeville 1979).

Lastly, we conducted a $\chi^{2}$ analysis to test for an effect of traffic volume on the probability of a frog successfully crossing the road, using only the data from frogs that were released near roads. All data were analyzed using SPSS 13.0 (SPSS Inc., 2004) and were checked for normality and homogeneity of variances before running ANOVA tests.

\section{RESULTS}

We captured and released 193 frogs, 60 at control sites, 66 at low-traffic sites, and 67 at high-traffic sites. All frogs released near roads attempted to cross the $10-\mathrm{m}$ band regardless of treatment. Treatment affected crossing time after controlling for a significant positive effect of temperature (Table 1), with the longest crossing time near hightraffic roads and the lowest crossing time near control sites (Fig. 2). 
Fig. 2. Mean and $95 \% \mathrm{CI}$ of the time taken for frogs to cross a 10-m band of habitat at control sites $(n=$ 60 frogs), and adjacent to low ( $n=62$ frogs) and high ( $n=67$ frogs) traffic roads.

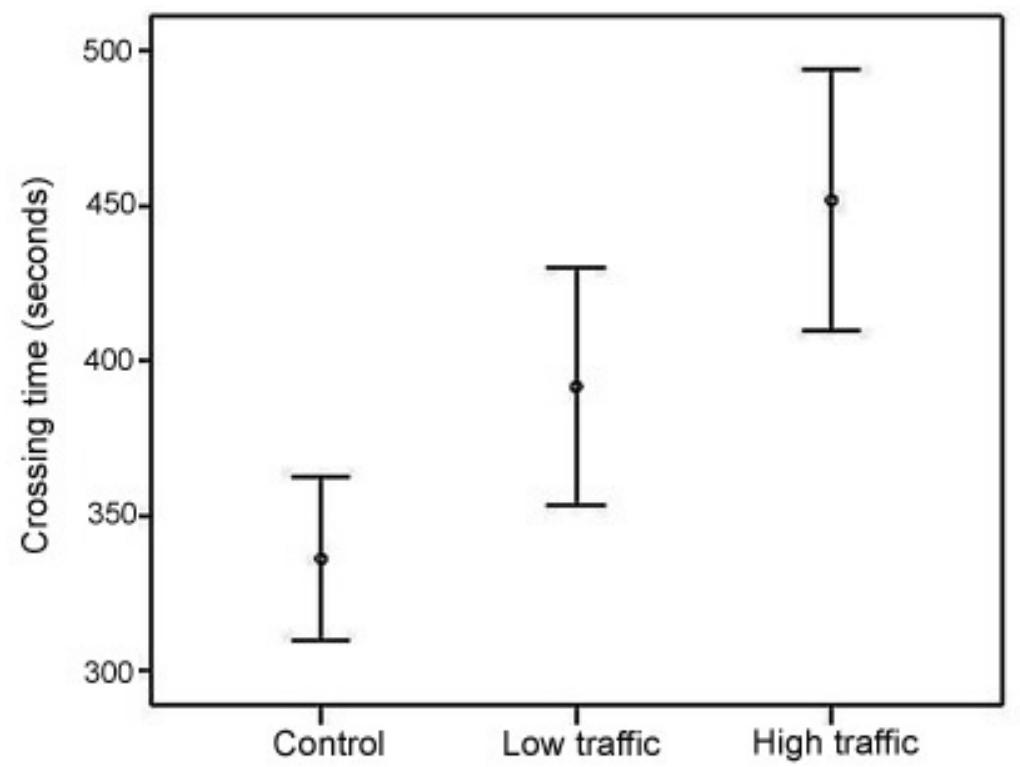

Results of the Mauchly's Test of Sphericity indicated that the assumption of sphericity was not violated in the within-subjects trials $(w=0.983$; df $=2 ; P=0.194$ ) for the interaction of distance, temperature, and traffic treatment on angular deviation. Therefore, we present data from the univariate analysis of variance in Table 2 . We found a significant interaction between distance to the road and traffic level on movement direction. Frogs had a greater tendency to deviate from a straight course toward the road as distance to the road decreased (Fig. 3).

There was a significant effect of traffic on the probability of crossing the road successfully $\left(\chi^{2}=\right.$ $11.99 ; \mathrm{df}=1 ; \mathrm{P}<0.0001)$. Of the 67 frogs that attempted to cross high-traffic roads, $72 \%$ were successful. Of the 66 frogs that attempted to cross low-traffic roads, $94 \%$ were successful.

\section{DISCUSSION}

Taken together, our results support the assumption that the reason for strong negative effects of roads on leopard frogs is the high mortality they suffer on roads, and that this high mortality is due to the fact that they do not strongly avoid roads or traffic. We found that frogs responded to the road and traffic, but this response did not lead to avoidance of the road per se. Northern leopard frog movements were slower in the vicinity of roads than non-roaded areas and were slower near high-traffic roads than near low-traffic roads. They also tended to deviate from a straight-line perpendicular path as they approached within $3.3 \mathrm{~m}$ of roads, although the degree of this deviation was not affected by traffic volume. However, all frogs released near roads did ultimately attempt to cross the road. Therefore, changes in movement speed and deviations in their pathways did not actually lead to significant road avoidance. Twenty-eight percent of the frogs attempting to cross the higher-traffic roads were killed by traffic. This is a very high mortality rate considering that there was, on average, only one vehicle passing per minute on these roads during the time period of the study.

In addition to the lack of significant avoidance of roads or traffic while approaching roads, the behavior of anurans once on the road increases their vulnerability to road mortality. Mazerolle et al. (2005) found that anurans on roads tended to remain immobile as vehicles approached, leading to slower 
Table 2. Within-subjects, Type III ANOVA assuming sphericity for the effect of distance to the road, traffic, and temperature on deviation from a straight-line course toward the road. Treatment refers to control, low-traffic and high-traffic sites.

\begin{tabular}{llll}
\hline \hline Variable & DF & F & P \\
\hline Distance & 2 & 8.558 & $<0.0001$ \\
Distance x Temperature & 2 & 4.486 & 0.012 \\
Distance x Treatment & 4 & 27.708 & $<0.0001$ \\
Error & 378 & & \\
\hline
\end{tabular}

movement across roads with more traffic. In our study, we also observed that northern leopard frogs increased their travel time on high-traffic roads by increasing the duration of between-hop pauses and by deviating from a perpendicular path across these roads (J. Bouchard, personal observation). Increased travel time across roads almost certainly increases the probability of traffic mortality, even if animals are small enough to pass beneath a vehicle bumper (Hels and Buchwald 2001, van Langevedle and Jaarsma 2005).

Due to our proximity to the frogs while they were moving through the study sites, as well as potential stress from capture and handling, it is possible that the behavior we observed is inconsistent with frog movements under more natural conditions. Although we cannot rule out this possibility, we feel that our results are consistent with unmanipulated frog movements. For example, if frogs were avoiding the observers or the flashlight, then we would expect at least some individuals to flee from us in the opposite direction that they were originally heading (i.e., they are avoiding us). However, we found no evidence in the field that frogs changed their direction of travel after release, suggesting that their motivation to cross the road outweighed whatever flight response they had from the observers. On the other hand, frogs may have chosen to respond to us as predators and remained motionless (Heinen 1994, Heinen and Hammond 1997), yet we did not observe this behavior after release as frogs continued to proceed toward the road following release.

Combined, the negative effects of traffic on frog populations and the miscued response of frogs to approaching vehicles indicate a mismatch between frogs' evolved movement behaviors and the humanaltered landscapes through which they must move (Fahrig 2007). Their slower movement in response to higher traffic volumes is consistent with frogs' documented prey defense strategy (Heinen 1994, Heinen and Hammond 1997). Thus, roads and vehicles represent an "evolutionary trap" (Schlaepfer et al. 2002) for leopard frogs. This is further supported by the finding that amphibian and reptile species that move more frequently and farther through the landscape are more susceptible to roads and human-modified landscape features than are more sedentary species (Gibbs 1998, Carr and Fahrig 2001, Roe et al. 2006). This result is particularly surprising because the relatively short generation time of amphibians, combined with a notable presence of roads and vehicles in our study area for the past 80 years or so, should be selecting for individuals that can avoid cars or roads.

Our conclusion, that the strong negative effect of roads on leopard frog populations is due to their lack of road avoidance and high resulting mortality, is consistent with other studies. Reptile species that show strong negative effects of roads on population size (e.g., large snakes) do not show behavioral avoidance of roads and, therefore, suffer very high road mortality, whereas populations of species that do show road avoidance behavior are much less likely to be affected by roads (Rudolph et al. 1999, Koenig et al. 2001, Andrews and Gibbons 2005, Row et al. 2007). Like amphibians, some snakes also stop or move more slowly on roads, increasing their vulnerability to road mortality (Andrews and Gibbons 2005). In contrast, studies on the effects of roads on small mammal abundances typically show 
Fig. 3. Angular deviation of movement direction. Frogs tend to deviate from movement directly toward the road within $3.3 \mathrm{~m}$ of the road surface. Movement bands 1, 2, and 3 at low- and high-traffic sites correspond to 10.0-6.7 m, 6.6-3.4 m, and 3.3-0.0 m from the road surface, respectively. At control sites, movement bands 1, 2, and 3 correspond to $10.0-6.7 \mathrm{~m}, 6.6-3.4 \mathrm{~m}$, and 3.3-0.0 $\mathrm{m}$ from the end of the 10-m monitoring area (see Fig. 1).

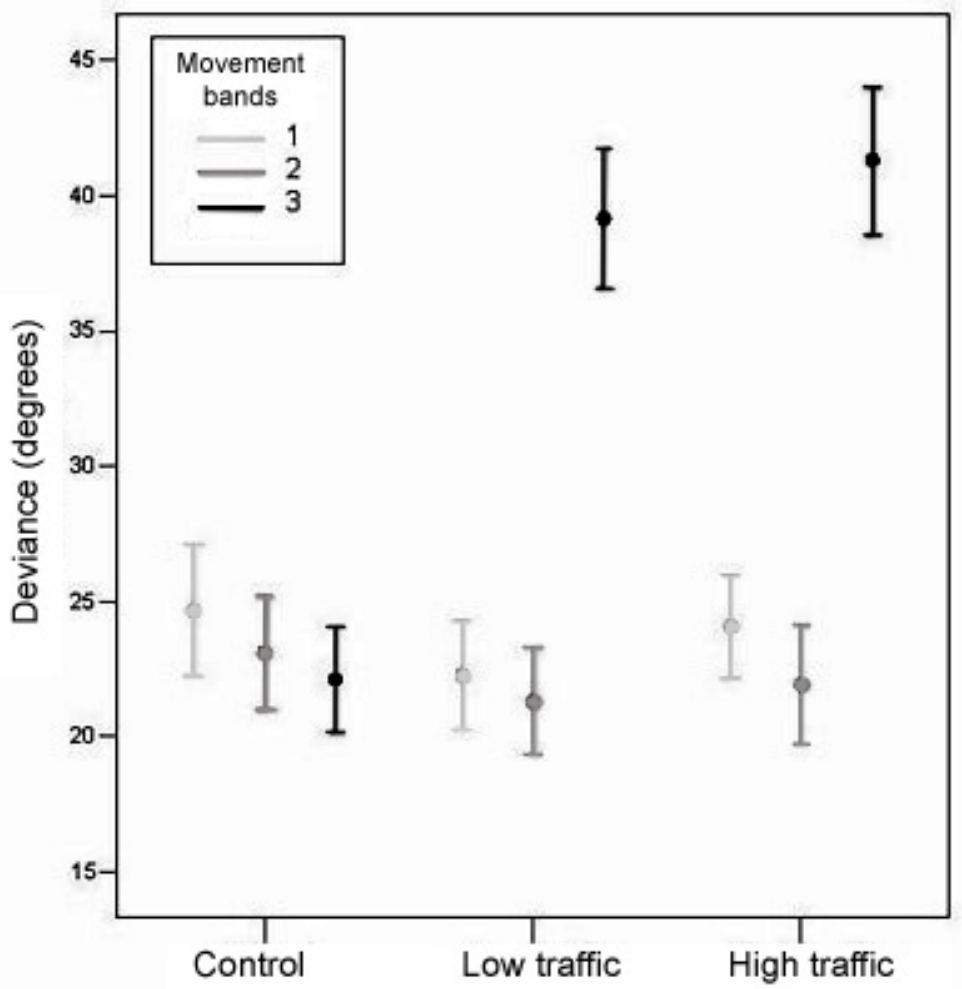

very weak effects (Adams and Geis 1983, Rosa and Bissonette 2007) or even positive effects (Johnson and Collinge 2004, Rytwinski and Fahrig 2007). Several studies have documented that small mammals avoid going onto roads, probably due to the lack of protective cover on the road surface (Oxley et al. 1974, Kozel and Fleharty 1979, Rico et al. 2007, Ford and Fahrig 2008, McGregor et al. 2008). Taken together, our results and these studies support the idea that populations of species that do not avoid roads are more likely to be negatively affected by roads than populations of species that behaviorally avoid roads, due to the higher level of road mortality on the non-road-avoiding species.

We would not expect to see the strong negative effect of roads on frog abundance (e.g., Carr and Fahrig 2001, Eigenbrod et al. 2008b), as well as an absence of road avoidance (our study), unless road mortality negatively affects frog populations. In our study area, when frogs approach roads there is a high probability that they will move onto the road surface because roads in our study area do not have adjacent fences or walls that would block frog movement (Dodd et al. 2004). Road mortality likely affects frog populations by decreasing the number of available breeding individuals for a particular cohort and by reducing genetic exchange between populations (Jaeger et al. 2005). As the probability of road mortality is positively correlated with traffic volume (Hels and Buchwald 2001, Gibbs and Shriver 2002), we would expect that the main highways in our area would have the greatest negative effect on local frog populations. Efforts to mitigate these effects should, therefore, prioritize areas where frog movements intersect with hightraffic roads. 
For the conservation of leopard frogs, and most likely many other amphibian species, the absence of road avoidance behavior means that frogs should be prevented from moving onto the road surface. Drift fences can be used to funnel frog movements to safe crossing areas (Clevenger et al. 2001, Woltz et al. 2008). Safe crossings can be provided by the modification of culverts or bridges to allow passage by herpetafauna (Dodd et al. 2004, Woltz et al. 2008). Additionally, modifying the behavior of drivers by using road signs that increase their alertness and decrease vehicle speed may also be appropriate in some areas. The effectiveness of these measures at conserving frog populations requires regional planning and prioritization of key movement areas where frogs are likely to encounter high levels of mortality.

Responses to this article can be read online at: http://www.ecologyandsociety.org/voll4/iss2/art23/ responses/

\section{Acknowledgments:}

We would like to thank Frederick Schueler, who helped us locate sites where leopard frogs move across roads and provided practical information about our field methods. We are also grateful to Sarah Brown for her help scouting potential field sites and organizing data and literature, and to a team of high school volunteers who helped with field work. This study was funded by a FQRNT (Fonds Québécois de la Recherche sur la Nature et les Technologies) scholarship to Julie Bouchard and a NSERC (Natural Sciences and Engineering Research Council of Canada) research grant to Lenore Fahrig. We thank three anonymous reviewers for useful comments on a previous draft.

\section{LITERATURE CITED}

Adams, L. W., and A. D. Geis. 1983. Effects of roads on small mammals. Journal of Applied Ecology 20:403-415.

Andrews, K. M., and J. W. Gibbons. 2005. How do highways influence snake movement? Behavioral responses to roads and vehicles. Copeia 4:772-782.
Boarman, W. I., and M. Sazaki. 2006. A highway's road-effect zone for desert tortoises (Gopherus agassizii). Journal of Arid Environments 65:94-101.

Carr, L., and L. Fahrig. 2001. Effect of road traffic on two amphibian species of differing vagility. Conservation Biology 15:1071-1078.

Clevenger, T., M. McIvor, D. McIvor, B. Chruszcz, and K. Gunson. 2001. Tiger salamander (Ambystoma tigrinum) movements and mortality on the Trans-Canada Highway in southwestern Alberta. Canadian Field Naturalist 115:199-204.

Dodd, N., W. J. Barichivich, and L. L. Smith. 2004. Effectiveness of a barrier wall and culverts in reducing wildlife mortality on a heavily traveled highway in Florida. Biological Conservation 118:619-631

Eigenbrod, F., S. J. Hecnar, and L. Fahrig. 2008a. Accessible habitat: an improved measure of the effects of habitat loss and roads on wildlife populations. Landscape Ecology 23:159-168.

Eigenbrod, F., S. J. Hecnar, and L. Fahrig. 2008b. The relative effects of road traffic and forest cover on anuran populations. Biological Conservation 141:35-46.

Fahrig, L. 2007. Non-optimal animal movement in human-altered landscapes. Functional Ecology 21:1003-1015.

Fahrig, L., J. H. Pedlar, S. E. Pope, P. D. Taylor, and J. F. Wegner. 1995. Effect of road traffic on amphibian density. Biological Conservation 73:177-182.

Ford, A. T., and L. Fahrig. 2008. Movement patterns of eastern chipmunks (Tamias striatus) near roads. Journal of Mammalogy 89:895-903.

Garland, T., and W. G. Bradley. 1984. Effects of a highway on Mojave Desert rodent populations. American Midland Naturalist 111:47-56.

Gibbs, J. P. 1998. Distribution of woodland amphibians along a forest fragmentation gradient. Landscape Ecology 13:263-268.

Gibbs, J. P., and G. Shriver. 2002. Estimating the effects of road mortality on turtle populations. Conservation Biology 16:1647-1652. 
Hels, T., and E. Buchwald. 2001. The effect of road kills on amphibian populations. Biological Conservation 99:331-340.

Henein, J. T. 1994. Behavior of newly metamorphosed American toads (Bufo a. americanus), and mechanisms of hunting by eastern garter snakes (Thamnophis s. sirtalis). Herpetologica 50:137-145.

Heinen, J. T., and G. Hammond. 1997 Antipredator behaviors of newly metamorphosed green frogs (Rana clamitans) and leopard frogs ( $\mathrm{R}$. pipiens) in encounters with eastern garter snakes (Thamnophis s. sirtalis). American Midland Naturalist 137:136-144.

Huynh, H., and G. K. Mandeville. 1979. Validity conditions in repeated measures designs. Psychological Bulletin 86:964-973.

Jaeger, J. A. G., J. Bowman, J. Brennan, L. Fahrig, D. Bert, J. Bouchard, N. Charbonneau, K. Frank, B. Gruber, and K. Tluk von Toschanowitz. 2005. Predicting when animal populations are at risk from roads: an interactive model of road avoidance behavior. Ecological Modeling 185:329-348.

Jaeger, J. A. G., and L. Fahrig. 2001. Modelling the effects of road network patterns on population persistence: relative importance of traffic mortality and "fence effect." Pages 298-312 in G. Evink, editor. Proceedings of the 2001 International Conference on Ecology and Transportation. North Carolina State University, Durham, North Carolina, USA.

Jensen, W. F., T. K Fuller, and W. L. Robinson. 1986. Wolf, Canis lupus, distribution on the Ontario-Michigan border near Sault Ste. Marie. Canadian Field-Naturalist 100:363-366.

Johnson, W. C., and S. K. Collinge. 2004. Landscape effects on black-tailed prairie dog colonies. Biological Conservation 115:487-497.

Koenig, J., R. Shine, and G. Shea. 2001. The ecology of an Australian reptile icon: how do bluetongued lizards (Tiliqua scincoides) survive in suburbia? Wildlife Research 28:215-227.
Kozel, R. M., and E. D. Fleharty. 1979. Movements of rodents across roads. Southwestern Naturalist 24:239-248.

Mazerolle, M., M. Hout, and M. Gravel. 2005. Behavior of amphibians on the road in response to car traffic. Herpetologica 61:380-388.

McGregor, R., D. J. Bender, and L. Fahrig. 2008. Do small mammals avoid roads because of the traffic? Journal of Applied Ecology 45:117-123.

Munguira, M. L., and J. A. Thomas. 1992. Use of road verges by butterfly and burnet populations, and the effect of roads on adult dispersal and mortality. Journal of Applied Ecology 29:316-329.

Oxley, D. J., M. B. Fenton, and G. R. Carmody. 1974. The effect of roads on populations of small mammals. Journal of Applied Ecology 11:51-59.

Pope, S. E., L. Fahrig, and H. G. Merriam. 2000. Landscape complementation and metapopulation effects on leopard frog populations. Ecology 81:2498-2508.

Rico A., P. Kindlmann, and F. Sedlacek. 2007. Barrier effects of roads on movements of small mammals. Folia Zoologica 56:1-12.

Roe, J. H., J. Gibson, and B. A. Kingsbury. 2006. Beyond the wetland border: Estimating the impact of roads for two species of water snakes. Biological Conservation 130:161-168.

Roedenbeck, I. A., L. Fahrig, C. S. Findlay, J. E. Houlahan, J. A. G. Jaeger, N. Klar, S. KramerSchadt, and E. A. van der Grift. 2007. The Rauischholzhausen agenda for road ecology. Ecology and Society 12(1): 11. [online] URL: http: //www.ecologyandsociety.org/vol12/iss1/art11/.

Roedenbeck, I. A., and P. Voser. 2008. Effects of roads on spatial distribution, abundance and mortality of brown hare (Lepus europaeus) in Switzerland. European Journal of Wildlife Research 54:425-437.

Rosa, S., and J. A. Bissonette 2005. How to teach a mule deer to safely cross an interstate highway: preliminary results of a wildlife mortality mitigation strategy on Interstate 15 in Utah, USA. Page 588 in 
C. Irwin, L. P. Garrett, and K. P. McDermott, editors. Proceedings of the 2005 International Conference on Ecology and Transportation. North Carolina State University, Durham, North Carolina, USA.

Row, J. R., G. Blouin-Demers, and P. J. Weatherhead. 2007. Demographic effects of road mortality in black rat snakes (Elaphe obsoleta). Biological Conservation 137:117-124.

Rudolph, D. C., S. J. Burgdorf, R. N. Conner, and R. R. Schaefer. 1999. Preliminary evaluation of the impact of roads and associated vehicular traffic on snake populations in eastern Texas. Pages ??? in $\mathrm{G}$. L. Evink, P. Garrett and D. Ziegler, editors. Proceedings of the Third International Conference on Wildlife Ecology and Transportation, FLER-73-99. Florida Department of Transportation, Tallahassee, Florida, USA.

Rytwinski, T. D. M., and L. Fahrig. 2007. Effect of road density on abundance of white-footed mice. Landscape Ecology 22:1501-1512.

Schlaepfer, M. A., M. C. Runge, and P. W. Sherman. 2002. Ecological and evolutionary traps. Trends in Ecology and Evolution 17:474-480.

SPSS, Inc.. 2004. SPSS for Windows, Release 13.0. SPSS, Inc., Chicago, Illinois, USA.

van Langevelde, F., and C. F. Jaarsma. 2005. Using traffic flow theory to model traffic mortality in mammals. Landscape Ecology 19:895-907.

Woltz, H. W., J. Gibbs, and P. K. Ducey. 2008. Road crossing structures for amphibians and reptiles: informing design through behavioral analysis. Biological Conservation 141:2745-2750. 